\title{
Ventricular assist devices as destination treatment. About one
}

\section{case}

Guillermo Careaga-Reyna*, Hugo Jesús Zetina-Tun, José Galván-Díaz and Luis Manuel Álvarez-Sánchez Instituto Mexicano del Seguro Social, Centro Médico Nacional La Raza, Hospital General "Dr. Gaudencio González Garza", Ciudad de México, Mexico

\begin{abstract}
The treatment of refractory terminal heart failure has been heart transplantation. However, there are limitations with regard to clinical conditions of the recipient and availability of donors, and ventricular support has therefore been alternatively used as destination therapy. We describe the case is of a female patient with ischemic cardiomyopathy-associated heart failure who had a left ventricular assist device successfully implanted and at eight months of the procedure was at functional class I, with no complications.
\end{abstract}

KEY WORDS: Terminal heart failure. Left ventricular support. Destination therapy. Heart transplantation. Ventricular assist device.

\section{Introduction}

End-stage heartfailure has increased in recent decades due to better medical and surgical treatments that prolong life, but not in all cases is myocardial damage progression prevented. Undoubtedly, heart transplantation is terminal heart failure definitive management, ${ }^{1}$ since it achieves a survival of 10.7 to 13.6 years. ${ }^{2}$ However, the main limitation is availability of appropriate donors, since less than $10 \%$ of cases are treated with 2,500 offered organs, for a potential demand of 250,000 patients requiring a heart transplant. Owing to this situation, the option of ventricular assist devices was sought as a therapeutic alternative. Currently, there are series that indicate that more than $40 \%$ of patients on transplant waiting list have a ventricular support system. $^{3}$
Life expectancy in Mexico is 75 years in men and 77 years in women. In 2002, the United States Food and Drug Administration approved the use of ventricular assist devices (VAD) as a bridge to heart transplantation in individuals who develop end-stage failure despite optimal therapy with inotropic support or in whom a prolonged waiting time is estimated. ${ }^{3}$ As of 2010, VADs were approved as destination treatment (DT) for the management of terminal heart failure. The indications for its implantation are very precise: bridge to cardiac transplant, bridge to another process to be determined, DT, bridge to recovery, rescue, etc.

Owing to the shortage of available heart grafts, VAD implantation has increased worldwide, especially as DT. VADs are of temporary (<30 days) or prolonged duration (> 30 days to years); they support and aid impaired cardiac function, improving patient clinical and functional status and quality of life.
Gac Med Mex. 2019;155:180-182

Contents available at PubMed www.gacetamedicademexico.com 
We present a case in where a prolonged ventricular support system was used as DT.

\section{Case presentation}

Sixty-eight-year-old woman with a history of dyslipidemia on treatment with atorvastatin and bezafibrate. She had suffered an acute myocardial infarction six years prior, without reperfusion treatment; she was discharged at 48 hours due to improved medical condition. Subsequently, she developed functional class progressive deterioration. Three months later, an implantable automatic defibrillator was placed in DD mode, with maximum frequency of 120 stimuli per minute, minimum frequency of 70 , ventricular tachycardia of 171 and ventricular fibrillation of 214. Six months after the implant, transplantation request was presented to the respective committee of the hospital where she was being treated; although it was accepted, in view of the lack of an appropriate donor and persistence of clinical deterioration, moderate effort angina, 15-kg weight loss and frequent hospital readmissions due to functional classes III to IV heart failure, the case was re-evaluated and placing a left VAD as DT was decided. On preoperative assessment, lithiasic cholecystitis was found; laparoscopic cholecystectomy was performed.

The echocardiogram showed a mitral valve with an area of $4 \mathrm{~cm}^{2}$, maximum velocity (Vmax) of 1.9 , without insufficiency; trivalve aortic valve, with an area of $2.22 \mathrm{~cm}^{2}, V \max$ of 1.9 , maximum gradient of $14 \mathrm{mmHg}$, without insufficiency; tricuspid valve with Vmax of 2.9 and moderate insufficiency; pulmonary artery systolic pressure of $43 \mathrm{mmHg}$, severe systolic dysfunction of the left ventricle with ejection fraction (LVEF $28 \%$ ), systolic diameter of $52 \mathrm{~mm}$ and diastolic of 64 , with $10-\mathrm{mm}$ interventricular septum thickness. The gamma scan showed anteroseptal infarction without myocardial viability. Findings on cardiac catheterization revealed left coronary trunk without lesions, anterior descending, Gensini 3, proximal and mid-segment focal ectasia, the rest of the vessel with diameter lower than $2 \mathrm{~mm}$, first diagonal without lesions, non-dominant circumflex artery, with no injuries, left ventricular branch and posterior descending without lesions. Left ventricular pressure was $107 / 79 \mathrm{mmHg}$, aorta $110 / 72 \mathrm{mmHg}$, pulmonary artery trunk $53 / 23 \mathrm{mmHg}$, right ventricle $51 / 2 \mathrm{mmHg}$, and right atrium $2 \mathrm{mmHg}$. Right pressure measurement was repeated and the results were right ventricle $46 / 6 \mathrm{mmHg}$, pulmonary artery $46 / 7 \mathrm{mmHg}$ and pulmonary capillary pressure of $4 \mathrm{mmHg}$.

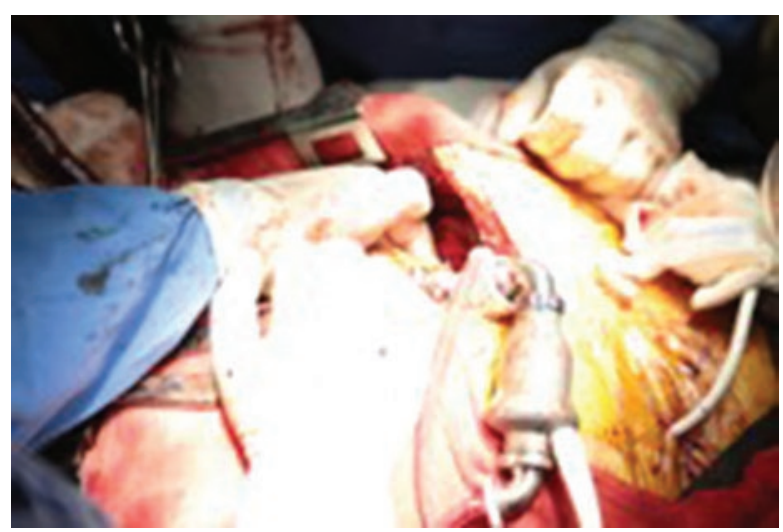

Figure 1. Implantation of the ventricular assist device in the subdiaphragmatic pouch.

With no contraindications for surgery and assessment with the Society of Thoracic Surgeons scale, $8.2 \%$ risk of mortality, $45 \%$ of morbidity, $38 \%$ of renal failure and $25 \%$ of reoperation need, implantation of ventricular assist device left Heart-Mate $\|^{\circledR}$ was decided.

The procedure was performed under balanced general anesthesia, through longitudinal medial sternotomy and with extracorporeal circulation support (Figures 1 and 2). It consisted in creating a subdiaphragmatic pouch for the pump system and implanting the blood outlet tube through the apex orifice of left ventricle, to pass through the pump in direction of a precoagulated graft that was anastomosed end-toside to the ascending aorta. The system was put into operation after externalization of the power supply cable and connection to the external battery. The cardiopulmonary bypass was gradually withdrawn and the support system progressively took over the pumping function. Careful hemostasis was performed and thoracic drains were placed to proceed to closure of the chest wall in the usual way. There were no postoperative complications and the patient remained on postoperative intensive therapy for 10 days, after which she was discharged to hospitalization, where the family and the patient were trained again in the use of the system, the change and charge of batteries, and usage options in order for the patient to be able to engage with her activities without complications. She was discharged from the hospital 28 days after implantation. At the moment of this report, she was in functional class I, she had regained weight and seven months after surgery she had no complications.

\section{Discussion}

The INTERMACS study is a registry of US patients who received mechanical ventricular support to treat 


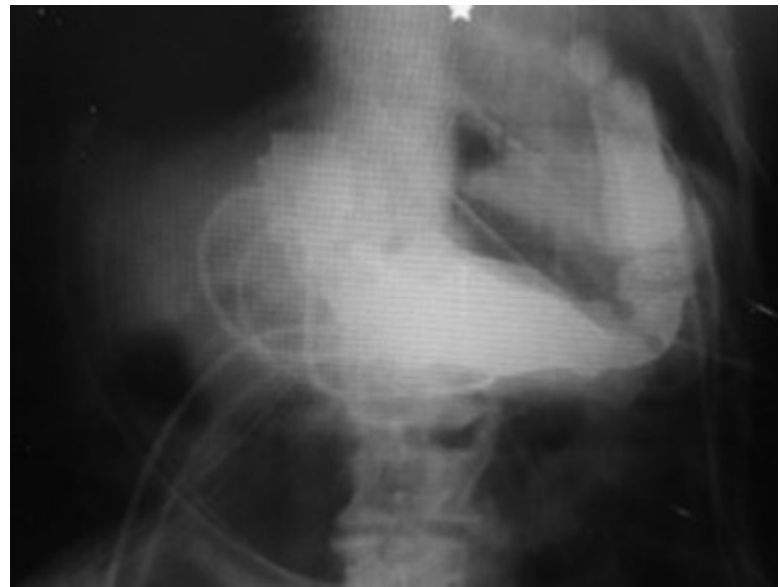

Figure 2. Postoperative radiological control for ventricular assist device appropriate position.

end-stage heart failure; seven indication levels were derived from this study according to the hemodynamic profile and functional capacity. ${ }^{4}$ Since the REMARCH 2001 study, where Heart Mate II was used, the implantation of VAD as DT was found to result in better one-year survival than management with medical therapy alone.

The ROADMAP ${ }^{5}$ study compared VAD implantation as DT versus medical treatment; although one-year mortality was similar (20\%), quality of life and functional capacity were improved in those who had the VAD implanted.

According to data from the ISHLT Mechanically Assisted Circulatory Support Registry Steering, until 2012, 6,000 devices had been implanted in the world and the main indication was DT (40\%) followed by bridge to heart transplant (39\%); the most common gender is the male gender $(78 \%)$ and the age interval these devices are most frequently placed is between 60 and 79 years (45\%), followed by 40 to 59 years (42\%).

The most frequently implanted VAD type is the left ventricular axial flow support type (99\%); Heart Mate II belongs to this group. Twelve- and 18-year survival rate is 78 and $71 \%$, respectively. Survival of patients with VAD as a bridge to heart transplantation at 12 and
18 months was 85 and $82 \%$, with better prognosis than patients managed with medical treatment alone.

The use of VAD as DT has improved the quality of life of individuals older than 75 years. A single study compared VAD as DT and heart transplant in the 65 to 72-year age group, with similar results at two years, although this resource would be of higher benefit in individuals younger than 60 years.

Chronic use of the device is not free of complications, since up to $20 \%$ of patients have been observed to experience control cord infections two years after implantation, $10 \%$, cerebrovascular events, and a higher frequency (50\%) has been observed of epistaxis or gastrointestinal bleeding episodes and lower frequency of thrombosis of the device; in $4 \%$, changing the controller has been necessary. ${ }^{6}$ VADs have managed to reduce the list of heart transplant recipients, to the point that it is thought that transplantation in the future will be an option for patients with VAD that experience complications by infections, thrombosis of the device or VAD malfunction, although the survival prognosis decreases if these complications are present at the time of transplantation.

As for cost-benefit, VAD is more expensive than heart transplantation with complications in the ensuing two years: infections (19\%), sepsis (19\%), stroke (12\%), hemorrhage $(54 \%)$ or right ventricular failure (18\%).

\section{References}

1. Careaga-Reyna G, Zetina-Tun H, Lezama-Urtecho CA. Programa de trasplante cardiaco de la Unidad Médica de Alta Especialidad, Hospital General Dr. Gaudencio González Garza del Centro Médico Nacional "La Raza". Rev Invest Clin. 2011;63:85-90.

2. Stehlik J, Edwards LB, Kucheryavaya AY, Benden C, Christie JD, Dobbels $F$, et al. The Registry of the International Society for Heart and Lung Transplantation: twenty-eighth adult heart transplant report-2011. J Heart Lung Transplant. 2011;30:1078-1094.

3. Mancini $\mathrm{D}$, Colombo PC. Left ventricular assist devices: a rapidly evolving alternative to transplant. J Am Coll Cardiol. 2015;65:2542-2555.

4. Kirklin JK, Naftel DC, Kormos RL, Pagani FD, Myers SL, Stevenson LW, et al. Interagency Registry for Mechanically Assisted Circulatory Support (INTERMACS) analysis of pump thrombosis in the HeartMate II left ventricular assist device. J Heart Lung Transplant. 2014;33:12-22.

5. Estep JD, Starling RC, Horstmanshof DA, Milano CA, Selzman CH, Shah KB, et al. Risk assessment and comparative effectiveness of left ventricular assist device and medical management in ambulatory heart failure patients: results from the ROADMAP. J Am Coll Cardiol. 2015;66:1747-1761.

6. Echeverría L, Salazar L, Torres A, Figueredo A. Dispositivos de asistencia ventricular: una realidad en Colombia. Rev Colomb Cardiol. 2016;23:49-54. 